Rev. Bras. Saúde Prod. Anim., Salvador, v.17, n.1, p.86-100 jan./mar., 2016 http://www.rbspa.ufba.br

\title{
Casca de banana em dietas para vacas mestiças em lactação
}

\author{
Banana Pell in diets for lactating crossbred cows
}

\author{
SOUZA, Criszoel Ferreira ${ }^{1}$; ROCHA JUNIOR, Vicente Ribeiro ${ }^{*}$; REIS, Sidnei \\ Tavares dos ${ }^{2}$; ANTUNES, Cláudia Ribeiro ${ }^{1}$; RIGUEIRA, João Paulo Sampaio ${ }^{1}$; \\ SALES, Eleuza Clarete Junqueira de ${ }^{1}$; SOARES, Camila ${ }^{1}$; SOUZA, Guilherme Reis ${ }^{1}$
}

\footnotetext{
${ }^{1}$ Universidade Estadual de Montes Claros, Departamento de Ciências Agrárias, Janaúba, Minas Gerais, Brasil.

${ }^{2}$ Universidade Federal de Sergipe, Departamento de Zootecnia, Aracajú, Sergipe, Brasil.

*Endereço para correspondência: vicente.rocha@unimontes.br
}

\section{RESUMO}

Objetivou-se avaliar consumo, digestibilidade, comportamento ingestivo e produção de leite de vacas F1 Holandês x Zebu alimentadas com dietas contendo casca de banana seca ao sol com ou sem adição de agentes químicos durante o processo de secagem. Utilizou-se dois quadrados latinos 4 x 4 , compostos por quatro dietas, quatro animais e quatro períodos experimentais. As dietas foram formuladas para ser isoprotéicas, com relação volumoso:concentrado de 75:25. Os tratamentos consistiram de $20 \%$ de inclusão da casca de banana seca com ou sem adição de $2 \%$ de calcário ou $2 \%$ de óxido de cálcio, em substituição à silagem de sorgo, além da dieta sem casca de banana. Foram utilizadas oito vacas com $80 \pm 10$ dias de lactação ao início do experimento, que teve duração de 72 dias, divididos em quatro períodos de 18 dias, com 14 dias de adaptação e quatro dias de coleta de amostras e dados. A casca de banana com óxido de cálcio reduziu os tempos de ruminação e mastigação total e o número de bolos ruminados por dia. Todavia, não alterou as eficiências de alimentação e ruminação da MS e FDN. A utilização da casca de banana seca ao sol em $20 \%$ da dieta não altera produção de leite, com produção média de $16,88 \mathrm{~kg}$ de leite com $3,5 \%$ de gordura.dia ${ }^{-1}$. Entretanto, reduz a digestibilidade da MS e dos nutrientes, podendo limitar o ganho de peso dos animais. A utilização de aditivos na secagem da casca de banana não melhora $\mathrm{o}$ consumo e produção de leite.

Palavras-chave: coproduto, consumo, digestibilidade, produção de leite

\section{SUMMARY}

The study purpose was to evaluate the intake, digestibility, ingestive behavior and milk production of F1 Holstein $\mathrm{x}$ Zebu cows fed with diets containing dried banana peel in the sun with or without addition of chemical agents during the drying process. We used two Latin squares $4 \times 4$, composed of four diets, four animals and four experimental periods. The diets were formulated to be isonitrogenious with forage to concentrate ratio of 75: 25 . Treatments consisted of $20 \%$ inclusion of dried banana peel with or without addition of $2 \%$ of limestone or $2 \%$ of calcium oxide, replacing the sorghum silage, apart from free banana peel diet. Were used eight cows with $80 \pm 10$ days in milk at the beginning of the experiment, which lasted 72 days, divided into four periods of 18 days with 14 days for diet adaptation and four days of sampling and data collection. The banana peel with calcium oxide decreases rumination time, the total chewing time and the number amounts ruminated per day. However, it didn't change the feed and rumination efficiencies of DM and NDF. The utilization of dried banana peel in the sun in $20 \%$ of the diet doesn't alter milk yield, with average production of $16.88 \mathrm{~kg}$ of milk with $3.5 \%$ of fat.day ${ }^{-1}$. However, reduces DM and nutrients digestibility, which may limit the weight gain of the animals. The use of additives in banana skin drying does not improve the consumption and production of milk.

Keywords: byproduct, digestibility, intake, milk production 
Rev. Bras. Saúde Prod. Anim., Salvador, v.17, n.1, p.86-100 jan./mar., 2016 http://www.rbspa.ufba.br

\section{INTRODUÇÃO}

Os resíduos da agroindústria mostramse como alternativas alimentares disponíveis e, na maioria dos casos, podem reduzir os custos de produção por substituírem alguns ingredientes, principalmente, os que apresentam custos mais elevados para as dietas de ruminantes (MURTA et al., 2011; URBANO et al., 2012; VIEIRA et al., 2010). Alternativas que considerem a redução do impacto ambiental, além do custo de produção são estrategicamente importantes para sustentabilidade dos sistemas produtivos (OLIVEIRA et al., 2014; FERREIRA et al., 2015).

A casca da banana é uma opção potencial para alimentação animal e se destaca por apresentar de 10 a $21 \%$ de pectina (MOHAPATRA et al., 2010), alto teor de carboidratos solúveis, que pode chegar a $32,4 \%$ da matéria seca dependendo da cultivar e teor de extrato etéreo que pode variar de 2 a 10,9\% (EMAGA et al., 2007; EMAGA et al., 2011). Todavia, a palatabilidade é uma característica do alimento que influencia diretamente o tempo de alimentação. Contudo, a casca de banana verde possui um sabor adstringente por possuir elevadas quantidades de taninos, podendo reduzir o consumo quando adicionada em altos níveis na dieta (MARTINEZ \& MOYANO, 2003).

O manejo da casca de banana tem dificultado a utilização por parte dos produtores devido ao alto teor de umidade (MONÇÃO et al., 2014a). Nesse sentido, o uso de agentes alcalinizantes como a cal virgem e o calcário na desidratação tem sido indicado como forma de acelerar $o$ processo de perda de água, além de conservar o produto por tempo maior. Porém, pouco se sabe sobre a quantidade a ser adicionada e o efeito causado por esses agentes alcalinos sobre o valor nutricional do co-produto. Segundo Lima et al. (2000), a desidratação das cascas de banana previne o crescimento e reprodução de microrganismos que causam deterioração, e minimiza reações oriundas de umidades elevadas. Aliado a isso, possibilita a redução de peso e volume, e o custo de transporte do produto. Carvalho et al. (2010), Macedo et al. (2011) e Ribeiro et al. (2009) verificaram que os agentes alcalinizantes como a cal virgem e calcário melhoram a degradabilidade da fração fibrosa de alimentos de baixo valor nutricional como a cana-de-açúcar.

Assim, objetivou-se avaliar o consumo, aspectos do comportamento ingestivo, digestibilidade dos nutrientes e produção de leite de vacas F1 Holandês $\mathrm{x}$ Zebu alimentada com dietas contendo casca de banana inteira desidratada ao sol com ou se adição de agentes químicos durante $\mathrm{o}$ processo de secagem.

\section{MATERIAL E MÉTODOS}

O experimento foi conduzido na Fazenda Experimental da Universidade Estadual de Montes Claros - UNIMONTES, localizada no município de Janaúba, no Norte de Minas Gerais, cujas coordenadas geográficas são $15^{\circ} 48^{\prime} 32^{\prime \prime}$ de latitude e $43^{\circ} 19^{\prime} 3^{\prime}$ ' de longitude, na altitude de $533 \mathrm{~m}$, onde o clima, segundo a classificação de Köppen, é do tipo Aw, caracterizado por um verão chuvoso e inverno seco.

Foram utilizadas oito vacas F1 Holandês/Zebu, todas de segunda ordem de parto, com período médio de lactação ao início do experimento de 80 \pm 10 dias, peso médio inicial de $470 \mathrm{~kg}$ e produção média diária de leite corrigida para $3,5 \%$ de gordura de $15 \mathrm{~kg}$. O 
delineamento experimental adotado foram dois quadrados latinos $4 \times 4$, compostos de quatro animais, quatro tratamentos e quatro períodos experimentais cada. Utilizou-se quatro dietas experimentais: dieta convencional com silagem de sorgo sem a inclusão da casca de banana (controle); casca de banana seca ao sol em substituição a silagem de sorgo em $20 \%$ da dieta; casca de banana seca ao sol com $2 \%$ de calcário em substituição a silagem de sorgo em $20 \%$ da dieta; casca de banana seca ao sol com $2 \%$ de óxido de cálcio em substituição a silagem de sorgo em $20 \%$ da dieta. A substituição da silagem de sorgo pela casca de banana foi feita com base na matéria seca. As cascas de banana seca foram secas ao sol, sobre lona preta, distribuídos em camada de aproximadamente $5 \mathrm{~cm}$ de espessura, sendo revolvidos três vezes ao dia, por aproximadamente 7 dias.

O experimento teve duração de 72 dias, dividido em quatro períodos de 18 dias, dos quais os 14 primeiros dias de cada período foram utilizados para adaptação dos animais às dietas, e os quatro últimos para coleta de dados e amostras. Os animais foram mantidos em galpão coberto com estrutura metálica onde continham as baias individuais com piso de cimento, separadas por estruturas de ferro, dotadas de cochos e bebedouros. As vacas foram ordenhadas com ordenhadeira mecânica, duas vezes ao dia, às $08 \mathrm{~h}$ e às $16 \mathrm{~h}$, com bezerro ao pé. As dietas tiveram sua formulação de acordo com o NRC (2001) para vacas com média de $470 \mathrm{~kg}$ de peso corporal e produção média de $15 \mathrm{~kg}$ de leite com $3,5 \%$ de gordura dia $^{-1}$ e foram formuladas para serem isoproteicas. As dietas foram fornecidas às vacas duas vezes por dia, às $07 \mathrm{~h}$ e às $15 \mathrm{~h}$. O volumoso principal foi a silagem de sorgo, entretanto a casca de banana seca ao sol com ou sem aditivo substituiu parcialmente a silagem de sorgo em $20 \%$ da dieta total, ou seja, o percentual de casca foi pré-fixado em $20 \%$ da dieta, sendo considerada como componente da fração volumosa da mesma (Tabela 1). Foram pesados e registrados diariamente todos os ingredientes da dieta respeitando-se a proporção de cada tratamento, colocandose nos respectivos cochos a silagem, a casca de banana seca e inteira (sem desintegrar) e misturada de concentrados de cada tratamento, como forma de dieta total. As sobras foram pesadas e registradas diariamente. $\mathrm{O}$ fornecimento das dietas foi ajustado de acordo com as sobras, mantendo-se uma relação volumoso:concentrado com base na MS de 75:25, de forma que as sobras representassem $5 \%$ da quantidade de matéria seca fornecida. O consumo foi calculado através da quantidade fornecida subtraída das sobras.

Nos últimos quatro dias de cada período experimental, amostras dos alimentos fornecidos, das sobras e das fezes foram recolhidas diariamente pela manhã e armazenadas em freezer. A amostra fecal foi colhida diretamente na ampola retal. No final do experimento, foi feita uma amostra composta por animal e por período, sendo pré-seca em estufa de ventilação forçada a $55^{\circ} \mathrm{C}$ por 72 horas. Posteriormente, as amostras foram moídas em moinho de facas com peneira de malha com crivos de $1 \mathrm{e}$ $2 \mathrm{~mm}$ de diâmetro, sendo as primeiras utilizadas para análises laboratoriais e as de $2 \mathrm{~mm}$ para incubação ruminal.

A composição química-bromatológica dos alimentos fornecidos, das sobras e das fezes dos animais foram determinadas no Laboratório de Análises de Alimentos do Departamento de Ciências Agrárias da UNIMONTES, Campus - Janaúba. As análises de matéria seca (MS) (método 930.15), cinzas (método 942.05), extrato etéreo (EE) (método 2003.05) e proteína 
Rev. Bras. Saúde Prod. Anim., Salvador, v.17, n.1, p.86-100 jan./mar., 2016 http://www.rbspa.ufba.br ISSN 15199940

bruta (PB) (método 990.09) foram realizados como descritos pela AOAC (2000). Analises de fibra em detergente neutro corrigido para cinzas e proteína (FDNcp) e fibra em detergente ácido foram realizadas conforme descrito por Detmann et al. (2012). Os compostos nitrogenados insolúveis em detergente neutro (NIDN) e em detergente ácido (NIDA) foram obtidos após extração das amostras nos detergentes neutro e ácido pelo método Kjeldahl, e a lignina foi obtida como descrito por Detmann et al. (2012). Os carboidratos não fibrosos (CNF) foram calculados de acordo com a equação descrita por Detmann \& Valadares Filho (2010): CNF $=100$ (\%PB $+\%$ FDNcp $+\% \mathrm{EE}+\%$ cinzas $)$. A proporção dos ingredientes e a composição química das dietas encontram-se na Tabela 1.

Tabela 1. Proporção dos ingredientes das dietas experimentais (\%) e composição química das dietas, na base da matéria seca (\%)

\begin{tabular}{|c|c|c|c|c|}
\hline \multirow[b]{2}{*}{ Ingredientes } & \multicolumn{4}{|c|}{ Dietas experimentais (\% MS) } \\
\hline & $\begin{array}{l}\text { Silagem de } \\
\quad \text { sorgo }\end{array}$ & $\begin{array}{c}\text { Silagem +Casca } \\
\text { Banana }\end{array}$ & $\begin{array}{l}\text { Silagem + Casca } \\
\text { Banana c/ calcário }\end{array}$ & $\begin{array}{l}\text { Silagem + Casca } \\
\text { Banana c/ óxido de } \\
\text { cálcio }\end{array}$ \\
\hline Silagem de sorgo & 75,00 & 55,00 & 55,00 & 55,00 \\
\hline $\begin{array}{l}\text { Casca de banana seca } \\
\text { ao sol }\end{array}$ & 0,00 & 20,00 & 0,00 & 0,00 \\
\hline $\begin{array}{l}\text { Casca com } 2 \% \text { de } \\
\text { calcário }\end{array}$ & 0,00 & 0,00 & 20,00 & 0,00 \\
\hline $\begin{array}{l}\text { Casca com } 2 \% \text { de } \\
\text { óxido de cálcio }\end{array}$ & 0,00 & 0,00 & 0,00 & 20,00 \\
\hline Farelo de Soja & 5,96 & 5,96 & 6,95 & 6,95 \\
\hline Milho grão moído & 18,54 & 18,54 & 17,55 & 17,55 \\
\hline${ }^{1}$ Suplemento mineral & 0,50 & 0,50 & 0,50 & 0,50 \\
\hline \multicolumn{5}{|c|}{ Composição química } \\
\hline Matéria Seca (\%) & 42,00 & 55,09 & 55,24 & 55,29 \\
\hline Matéria Orgânica (\%) & 93,01 & 91,50 & 90,42 & 90,34 \\
\hline Proteína Bruta (\%) & 10,62 & 10,76 & 11,15 & 11,14 \\
\hline${ }^{2} \mathrm{NIDN}$ (\% do N-total) & 4,91 & 6,16 & 6,20 & 6,35 \\
\hline${ }^{3}$ NIDA ( $\%$ do N-total) & 4,52 & 5,68 & 5,71 & 5,85 \\
\hline Extrato Etéreo (\%) & 2,40 & 3,75 & 3,34 & 3,63 \\
\hline $\begin{array}{l}\text { Carboidratos não } \\
\text { fibrosos }(\%)\end{array}$ & 20,30 & 20,49 & 19,81 & 20,70 \\
\hline${ }^{4} \mathrm{FDNcp}(\%)$ & 59,69 & 56,51 & 56,12 & 54,88 \\
\hline $\begin{array}{l}\text { Fibra em detergente } \\
\text { ácido }(\%)\end{array}$ & 31,56 & 32,72 & 32,39 & 31,42 \\
\hline Lignina & 8,19 & 10,29 & 10,94 & 10,63 \\
\hline
\end{tabular}

A estimativa da produção de MS fecal foi feita empregando-se a fibra em detergente ácido indigestível (FDAi) como indicador interno, sendo que as amostras dos alimentos, das sobras e das fezes foram incubadas em um novilho fistulado durante 288 horas para a realização de estimativas de produção 
Rev. Bras. Saúde Prod. Anim., Salvador, v.17, n.1, p.86-100 jan./mar., 2016 http://www.rbspa.ufba.br

fecal (DETMANN et al., 2012). O animal foi confinado na Fazenda Experimental da UNIMONTES, Campus Janaúba/MG. Após o período de incubação, as amostras foram retiradas do rúmen, lavadas e analisadas quanto aos teores de FDA para determinação da fração da fibra remanescente, considerada FDAi (Tabela 2). A produção de MS fecal foi estimada por meio da divisão entre o consumo do indicador pela sua concentração nas fezes. Para a determinação da digestibilidade foi utilizado o coeficiente de digestibilidade aparente. A partir dos resultados dos coeficientes de digestibilidade, foram calculados os nutrientes digestíveis totais (NDT) (SNIFFEN et al., 1992), considerando-se para o cálculo a FDNcp.

Tabela 2. Composição química dos ingredientes das dietas experimentais, com base na matéria seca

\begin{tabular}{|c|c|c|c|c|c|c|}
\hline \multirow[b]{2}{*}{ Itens } & \multicolumn{6}{|c|}{ Composição Química } \\
\hline & $\begin{array}{c}\text { Silagem } \\
\text { de } \\
\text { Sorgo }\end{array}$ & $\begin{array}{l}\text { Casca de } \\
\text { Banana }\end{array}$ & $\begin{array}{c}\text { Casca de } \\
\text { Banana }+ \\
2 \% \text { Calcário }\end{array}$ & $\begin{array}{l}\text { Casca de Banana }+2 \% \\
\text { óxido de Cálcio }\end{array}$ & $\begin{array}{l}\text { Milho } \\
\text { grão } \\
\text { moído }\end{array}$ & $\begin{array}{c}\text { Farelo } \\
\text { de } \\
\text { Soja } \\
\end{array}$ \\
\hline $\begin{array}{l}\text { Matéria } \\
\text { Seca }\end{array}$ & 31,62 & 91,68 & 92,43 & 92,69 & 91,09 & 91,45 \\
\hline $\begin{array}{l}\text { Matéria } \\
\text { Orgânica }\end{array}$ & 92,69 & 86,01 & 81,13 & 80,72 & 98,64 & 93,59 \\
\hline Proteína Bruta & 8,12 & 8,82 & 8,74 & 8,67 & 8,60 & 49,28 \\
\hline $\begin{array}{l}{ }^{1} \text { NIDA }(\% \\
\text { do N-total) }\end{array}$ & 4,03 & 9,80 & 9,66 & 10,34 & 4,44 & 11,31 \\
\hline $\begin{array}{l}\text { Extrato } \\
\text { Etéreo }\end{array}$ & 1,74 & 8,46 & 6,37 & 7,81 & 4,18 & 5,34 \\
\hline${ }^{2}$ FDNcp & 67,82 & 55,90 & 54,13 & 50,16 & 36,17 & 26,30 \\
\hline Lignina & 10,11 & 20,61 & 23,94 & 22,40 & 2,87 & 1,27 \\
\hline${ }^{3} \mathrm{CNF}$ & 15,01 & 12,83 & 11,89 & 14,08 & 48,70 & 11,73 \\
\hline
\end{tabular}

${ }^{1} \mathrm{NIDA}=$ nitrogênio insolúvel em detergente ácido $;{ }^{2} \mathrm{FDNcp}=$ Fibra em detergente neutro corrigida para cinza e proteína; ${ }^{3} \mathrm{CNF}=$ Carboidratos não fibrosos.

As oito vacas foram submetidas à observação visual para avaliação do comportamento ingestivo em dois dias consecutivos de cada período experimental após adaptação à nova dieta. No primeiro dia foi feita a observação visual de cada animal a cada 5 minutos, durante 24 horas, para determinação dos tempos despendidos com alimentação, ruminação e ócio, de acordo com metodologia descrita por Johnson \& Combs (1991). No dia subsequente, foram realizadas as contagens do número de mastigações merícicas/bolo ruminal e a determinação do tempo despendido na ruminação de cada bolo ruminal, para cada animal, com a utilização de um cronômetro digital. Os valores do tempo despendido e do número de mastigações merícicas por bolo ruminal foram obtidos a partir das observações feitas durante a ruminação de três bolos ruminais, em três períodos diferentes do dia (10 às $12 \mathrm{~h}$; 13 às $15 \mathrm{~h}$ e 18 às $20 \mathrm{~h}$ ) de acordo com metodologia descrita por Burger et al. (2000). Durante a observação noturna das vacas, o ambiente foi mantido com iluminação artificial, estabelecida três dias antes da avaliação do comportamento ingestivo 
Rev. Bras. Saúde Prod. Anim., Salvador, v.17, n.1, p.86-100 jan./mar., 2016 http://www.rbspa.ufba.br

para que os animais se adaptassem a essa condição.

A eficiência de alimentação (EA), a eficiência de ruminação (ER), o número de bolos ruminais por dia (NBR), o tempo de mastigação total (TMT) e o número de mastigações merícicas por dia $(\mathrm{NM} /$ dia) foram obtidos segundo técnica descrita por Burger et al. (2000). Durante os quatro últimos dias de cada período experimental, foram registradas as produções de leite por vaca. As amostras de leite de cada animal foram coletadas duas vezes ao dia, nos últimos quatro dias de cada período, sendo feito um pool das amostras do leite da ordenha da manhã e da tarde, proporcionalmente à quantidade produzida de manhã e à tarde. Após a ordenha de cada vaca, o leite foi homogeneizado e coletado uma amostra de 500mL. Posteriormente, essas amostras foram encaminhadas ao Laboratório de Tecnologia de Produtos de Origem Animal da Unimontes Campus de Janaúba e no mesmo dia foram determinados o teor de gordura. As produções de leite corrigidas para $3,5 \%$ de gordura foram calculadas utilizando-se a equação proposta por Sklan et al. (1994).

Os animais foram pesados em balança mecânica e avaliado seu escore de condição corporal (ECC), de 1 (animal extremamente magro) à 5 (animal extremamente gordo) por um único avaliador no início e ao final de cada período experimental, segundo metodologia descrita por Wildman et al. (1982).

Os dados obtidos foram submetidos à análise de variância pelo programa SISVAR (FERREIRA, 2011), sendo o peso inicial dos animais estabelecido com co-variável. Quando significativas, as médias dos tratamentos foram comparadas pelo teste de Tuckey ao nível de $5 \%$ de probabilidade.

\section{RESULTADOS E DISCUSSÃO}

O consumo de matéria seca (MS) teve valor médio de $16,48 \mathrm{~kg} \cdot \mathrm{dia}^{-1}$ (Tabela 3 ), correspondente a $3,47 \%$ do peso corporal das vacas. A inclusão de $20 \%$ de casca de banana em substituição a silagem sorgo, seja pura ou com $2 \%$ de aditivo (calcário e cal virgem) não influenciou $(\mathrm{P}>0,05)$ no consumo de MS.

$\mathrm{O}$ consumo de proteína bruta $(\mathrm{PB})$ não foi influenciado $(\mathrm{P}>0,05)$ pela inclusão de $20 \%$ de casca de banana seca ao sol, com ou sem adição dos agentes químicos, o que pode ser explicado pelo fato das dietas apresentarem teores de PB semelhantes. Ressalta-se ainda, a similaridade entre os teores de PB da silagem de sorgo $(8,12 \%)$ e da casca de banana $(8,82 \%)$ (Tabela 2$)$.

Divergindo dos resultados deste trabalho, Ribeiro et al. (2009) avaliaram o valor nutricional de cana-de-açúcar tratada com $2,25 \%$ de cal virgem, e observaram redução de $13,63 \%$ no teor de $\mathrm{PB}$ em relação ao tratamento controle. De acordo com Oliveira et al. (2008), o óxido de cálcio proporciona o rompimento das pontes de hidrogênio entre os componentes da fibra, podendo implicar em outras alterações nos demais nutrientes, como liberação de proteína e minerais retidos na fibra.

Dormond et al. (1998) avaliaram níveis (14 e $21 \mathrm{~kg}$ ) crescentes de inclusão de casca de banana em dietas de vacas leiteiras e encontraram teor de $\mathrm{PB}$ de $10,45 \%$ e consumo de $110 \mathrm{~g}$ a mais de PB para o nível de inclusão de $21 \mathrm{~kg}$ de casca de banana, enquanto nesta pesquisa foi observado teor de $\mathrm{PB}$ de $8,82 \%$, e os níveis de inclusão não alteraram o consumo. A variação do teor de proteína bruta pode estar relacionada com as diferentes variedades de banana existentes. 
Rev. Bras. Saúde Prod. Anim., Salvador, v.17, n.1, p.86-100 jan./mar., 2016 http://www.rbspa.ufba.br ISSN 15199940

Tabela 3. Consumo médio diário de matéria seca (MS), proteína bruta (PB), fibra em detergente neutro (FDN), fibra em detergente ácido (FDA), carboidratos não fibrosos (CNF), extrato etéreo (EE) e nutrientes digestíveis totais (NDT) por vacas em lactação alimentadas com dietas contendo casca de banana

\begin{tabular}{|c|c|c|c|c|c|c|}
\hline \multirow[b]{2}{*}{ Itens } & \multicolumn{4}{|c|}{ Tratamentos } & \multirow[b]{2}{*}{$\begin{array}{l}\mathrm{CV} \\
(\%)\end{array}$} & \multirow[b]{2}{*}{$\operatorname{Pr}>c$} \\
\hline & $\begin{array}{l}\text { Silagem de } \\
\text { sorgo }\end{array}$ & $\begin{array}{c}\text { Silagem }+ \\
\text { Casca } \\
\text { Banana }\end{array}$ & $\begin{array}{l}\text { Silagem + Casca } \\
\text { Banana c/ calcário }\end{array}$ & $\begin{array}{c}\text { Silagem + Casca } \\
\text { Banana c/ óxido de } \\
\text { cálcio }\end{array}$ & & \\
\hline \multicolumn{7}{|c|}{ Consumo (Kg.dia $\left.{ }^{-1}\right)$} \\
\hline MS & $16,80^{\mathrm{A}}$ & $16,42^{\mathrm{A}}$ & $16,82^{\mathrm{A}}$ & $15,86^{\mathrm{A}}$ & 8,18 & 0,4622 \\
\hline PB & $1,81^{\mathrm{A}}$ & $1,78^{\mathrm{A}}$ & $1,92^{\mathrm{A}}$ & $1,81^{\mathrm{A}}$ & 7,91 & 0,2341 \\
\hline FDN & $10,22^{\mathrm{A}}$ & $9,79^{\mathrm{A}}$ & $10,08^{\mathrm{A}}$ & $9,14^{\mathrm{A}}$ & 8,45 & 0,0711 \\
\hline FDA & $4,87^{\mathrm{A}}$ & $4,97^{\mathrm{A}}$ & $5,06^{\mathrm{A}}$ & $4,54^{\mathrm{A}}$ & 9,22 & 0,1338 \\
\hline CNF & $3,49^{\mathrm{A}}$ & $3,41^{\mathrm{A}}$ & $3,28^{\mathrm{A}}$ & $3,37^{\mathrm{A}}$ & 8,61 & 0,5521 \\
\hline $\mathrm{EE}$ & $0,41^{\mathrm{C}}$ & $0,57^{\mathrm{A}}$ & $0,51^{\mathrm{B}}$ & $0,52^{\mathrm{AB}}$ & 8,76 & 0,0000 \\
\hline NDT & $9,51^{\mathrm{A}}$ & $7,62^{\mathrm{B}}$ & $7,92^{\mathrm{B}}$ & $8,59^{\mathrm{AB}}$ & 12,19 & 0,0063 \\
\hline \multicolumn{7}{|c|}{ Consumo (\%.Peso Corporal $\left.^{-1}\right)$} \\
\hline MS & $3,48^{\mathrm{A}}$ & $3,46^{\mathrm{A}}$ & $3,58^{\mathrm{A}}$ & $3,34^{\mathrm{A}}$ & 5,06 & 0,0855 \\
\hline FDN & $2,13^{\mathrm{B}}$ & $2,07^{\mathrm{AB}}$ & $2,14^{\mathrm{B}}$ & $1,92^{\mathrm{A}}$ & 5,28 & 0,0016 \\
\hline FDA & $1,01^{\mathrm{AB}}$ & $1,05^{\mathrm{B}}$ & $1,07^{\mathrm{B}}$ & $0,95^{\mathrm{A}}$ & 5,78 & 0,0020 \\
\hline
\end{tabular}

Médias nas linhas seguidas pela mesma letra não diferem $(\mathrm{P}>0,05)$ entre si pelo teste de Tukey.

Não foram observadas diferenças $(\mathrm{P}>0,05)$ para consumo de fibra em detergente neutro (FDN), apesar da casca de banana ter uma menor proporção de FDN em sua composição $(55,45 \%)$ comparando com a silagem de sorgo (69,24\%). Possivelmente, o aumento do teor de MS das dietas com casca em relação à dieta sem casca, compensou o consumo de FDN, apesar do menor teor desta fração naquelas dietas. Entretanto, o consumo de FDN em porcentagem do peso corporal diminuiu para o tratamento em que a silagem foi substituída pela casca de banana com óxido de cálcio (cal virgem). $\mathrm{O}$ tratamento com cal favoreceu uma redução da FDN da casca de banana e, consequentemente, da dieta.

Comportamento semelhante pode ser observado para o consumo de FDA. Possivelmente, o óxido de cálcio agiu quebrando ligações hidrogênicas entre lignina e celulose da casca de banana, solubilizando uma maior proporção de nutrientes ao ambiente ruminal (Tabela 3).

A inclusão de $20 \%$ de casca de banana com ou sem aditivo na dieta de vacas F1 Holandês/Zebu em lactação, em substituição à silagem de sorgo, não alterou o consumo dos carboidratos não fibrosos (CNF) $(\mathrm{P}>0,05)$.

$\mathrm{O}$ consumo de extrato etéreo foi superior $(\mathrm{P}<0,05)$ nas dietas com casca de banana, justificado pela maior concentração de EE nestas dietas, tendo em vista a maior proporção deste componente na casca de banana $(7,55 \%)$ em relação à silagem de sorgo $(1,74 \%)$.

Apesar de aumentar os teores de extrato etéreo na dieta, a inclusão de $20 \%$ de casca de banana seca manteve teor médio de EE nessas dietas de 3,57\% da MS total, não representando risco a fermentação ruminal. Palmquist \& Mattos (2006) determinaram que teores superiores a $50 \mathrm{~g} \cdot \mathrm{kg}^{-1}$ ou $5 \%$ de extrato 
Rev. Bras. Saúde Prod. Anim., Salvador, v.17, n.1, p.86-100 jan./mar., 2016 http://www.rbspa.ufba.br ISSN 15199940

etéreo na dieta podem comprometer o consumo de matéria seca, seja por mecanismos regulatórios que controlam a ingestão de alimentos, seja pela capacidade limitada dos ruminantes de oxidar os ácidos graxos.

De modo geral, a digestibilidade nas dietas com casca de banana (Tabela 4) foi prejudicada pelo maior teor de lignina da casca, entretanto, o consumo de MS não foi alterado. Isto determina que, a maior concentração de lignina presente na casca de banana, está ligada diretamente na fibra e na PB da parece celular, comprovada pelo alto teor de NIDN, NIDA, FDN e FDA das dietas que continham cascas de banana substituindo a silagem de sorgo.

Tabela 4. Digestibilidade aparente total da matéria seca (MS), proteína bruta (PB), extrato etéreo (EE), fibra em detergente neutro (FDN), fibra em detergente ácido (FDA), carboidratos não fibrosos (CNF) e nutrientes digestíveis totais (NDT) de dietas com casca de banana fornecidas a vacas em lactação

\begin{tabular}{lcccccc}
\hline \multirow{2}{*}{ Itens } & \multicolumn{5}{c}{ Tratamentos } & Silagem de \\
\cline { 2 - 5 } & Sorgo & $\begin{array}{c}\text { Silagem }+ \\
\text { Casca Banana }\end{array}$ & $\begin{array}{c}\text { Silagem + Casca } \\
\text { Banana c/ calcário }\end{array}$ & $\begin{array}{c}\text { Silagem + Casca } \\
\text { Banana c/ óxido de } \\
\text { cálcio }\end{array}$ & $\begin{array}{c}\text { CV } \\
(\%)\end{array}$ & Pr>Fc \\
\hline MS & $59,53^{\mathrm{A}}$ & $50,62^{\mathrm{B}}$ & $52,12^{\mathrm{AB}}$ & $58,08^{\mathrm{AB}}$ & 11,47 & 0,0236 \\
PB & $50,01^{\mathrm{A}}$ & $37,40^{\mathrm{B}}$ & $39,14^{\mathrm{B}}$ & $47,17^{\mathrm{AB}}$ & 16,95 & 0,0056 \\
EE & $64,12^{\mathrm{A}}$ & $45,42^{\mathrm{B}}$ & $49,12^{\mathrm{B}}$ & $65,63^{\mathrm{A}}$ & 15,70 & 0,0001 \\
FDN & $55,36^{\mathrm{A}}$ & $44,91^{\mathrm{B}}$ & $45,10^{\mathrm{B}}$ & $50,24^{\mathrm{AB}}$ & 14,25 & 0,0194 \\
FDA & $47,34^{\mathrm{A}}$ & $39,58^{\mathrm{AB}}$ & $33,09^{\mathrm{B}}$ & $39,46^{\mathrm{AB}}$ & 24,24 & 0,0470 \\
$\mathrm{CNF}$ & $68,77^{\mathrm{A}}$ & $62,28^{\mathrm{A}}$ & $67,70^{\mathrm{A}}$ & $74,77^{\mathrm{A}}$ & 12,23 & 0,0527 \\
NDT* & $56,65^{\mathrm{A}}$ & $46,82^{\mathrm{B}}$ & $47,56^{\mathrm{B}}$ & $54,64^{\mathrm{AB}}$ & 12,49 & 0,0104 \\
\hline
\end{tabular}

Médias nas linhas seguidas pela mesma letra não diferem $(\mathrm{P}>0,05)$ entre si pelo teste de Tukey.

*Calculados através da equação de Sniffen et al. (1992).

Segundo Van Soest (1994), os teores de nitrogênio insolúvel em detergente ácido dos alimentos interferem na digestibilidade da proteína bruta, o que poderia explicar a queda da digestibilidade da proteína bruta e a redução no seu aproveitamento, devido ao aumento nos teores e no consumo de proteína insolúvel em detergente ácido. Clementino (2008) determinou que os subprodutos da produção de banana, é uma alternativa interessante de alimento para ruminantes, notadamente por possuir a maioria dos nutrientes requeridos por esses animais. Entretanto o subproduto do processamento da banana, composto essencialmente de cascas e frutos refugos, não deve ser utilizado como única fonte de alimento para ruminantes. Apesar de ter favorecido o aumento no consumo de proteína bruta $(\mathrm{PB})$, extrato etéreo $(\mathrm{EE})$ e nutrientes digestíveis totais (NDT) em dietas para ovinos, houve aumento nos teores de nitrogênio insolúvel em detergente ácido (NIDA), o que pode interferir na quantidade de nitrogênio disponível para o animal e com isso reduzir as digestibilidades da MS, PB, FDA, além do balanço nitrogenado. Sugeriu que o mesmo fosse utilizado com fonte protéica associada.

$\mathrm{O}$ que se observou no presente estudo foi que a inclusão de $20 \%$ de casca de banana implicou na diminuição da digestibilidade da proteína bruta, 
todavia, no tratamento da casca de banana com óxido de cálcio isto não foi verificado. Possivelmente a cal virgem proporcionou uma melhora na digestibilidade da casca de banana, rompendo as ligações hidrogênicas da lignina com a proteína da parece celular (MONÇÃO et al., 2014b).

É importante ressaltar a presença de compostos fenólicos, principalmente taninos, na casca de banana (BORGES et al., 2009). Estes compostos possuem a habilidade de ligar-se a proteínas, combinar-se com celulose e pectina para formar complexos insolúveis, fazendo com que esses carboidratos e essas proteínas fiquem indisponíveis para o animal (OLIVEIRA \& BERCHILLI, 2007). Neste sentido, deve-se considerar que a redução da digestibilidade da PB nas dietas com casca de banana pode está também relacionada a um possível incremento nos níveis de taninos.

A digestibilidade dos $\mathrm{CNF}$ não foi diferente $(\mathrm{P}>0,05)$ entre as dietas. Desta forma, pode-se afirmar que a diferença entre as dietas, com ou sem casca de banana, estão ligadas aos componentes da parede celular, possivelmente ao alto teor de lignina das cascas de banana, indisponibilizando proteínas e carboidratos fibrosos que poderiam ser digeridos no ambiente ruminal. Segundo Omer (2009), a casca de banana apresenta elevada fração "a" (açúcares solúveis) em relação há outros alimentos volumosos, o que promove rápido crescimento microbiano no rúmen. Entretanto, a baixa taxa de degradação ruminal da fração potencialmente degradável "b" pode reduzir a ingestão de MS e a disponibilidade de energia, o que pode limitar o desempenho produtivo dos animais.

A digestibilidade aparente do extrato etéreo (DEE) nas dietas foi influenciada
$(\mathrm{P}<0,05)$ pela fonte volumosa utilizada (Tabela 4). Os melhores valores foram observados na dieta controle, sem casca, e na dieta com casca tratada com cal virgem. Uma possibilidade é que o cálcio do calcário ligou-se aos ácidos graxos da casca de banana formando sabões de cálcio (GONZALEZ et al., 1998), o que pode ter prejudicado a digestibilidade do extrato etéreo. Segundo Antunes (2013), a casca de banana apresentou em seu perfil de ácidos graxos, $62,87 \%$ de saturados, o que pode contribuir para diminuição da digestibilidade do extrato etéreo nas dietas com inclusão de casca de banana. Pimentel (2015) constatou redução linear da digestibilidade do extrato etéreo com a inclusão de casca de banana na dieta de vacas em lactação.

A substituição de silagem de sorgo pela casca de banana com ou sem aditivo, em $20 \%$ da dieta, não influenciou $(\mathrm{P}>0,05)$ o tempo em que as vacas permaneceram alimentando, com média de 6,07h (Tabela 5), corroborando com os consumos de MS e FDN, que também foram semelhantes entre as diferentes dietas experimentais. $\mathrm{O}$ uso de óxido de cálcio na casca de banana reduziu $\mathrm{o}$ teor de fibra da dieta, entretanto não diminuiu o tempo de alimentação.

As vacas alimentadas com a dieta contendo casca de banana seca ao sol com óxido de cálcio apresentaram o menor tempo de ruminação $(8,01 \mathrm{~h}) \mathrm{em}$ relação àquelas alimentadas com a dieta controle $(9,07 \mathrm{~h})$, o que pode ser explicado pelos menores teores de FDN nas dietas com casca, além do possível efeito do óxido de cálcio na solubilização de componentes da parede celular (RIBEIRO et al., 2009); Macedo et al., 2011). Acompanhando as variações no tempo de ruminação, o tempo em ócio das vacas foi menor na dieta sem casca $(\mathrm{P}<0,05)$ comparada à 
Rev. Bras. Saúde Prod. Anim., Salvador, v.17, n.1, p.86-100 jan./mar., 2016 http://www.rbspa.ufba.br ISSN 15199940

dieta com casca de banana seca ao sol com óxido de cálcio.

O período de ócio é o tempo em que o animal descansa, reduzindo ao máximo os gastos de energia, sendo um parâmetro importante para os sistemas de produção animal. Geralmente, o tempo de ócio aumenta com dietas de maior densidade energética e reduz quando aumenta a fibra, em função do aumento nos tempos de alimentação e ruminação (VAN SOEST, 1994).

Tabela 5. Variáveis do comportamento ingestivo de vacas em lactação alimentadas com dietas contendo casca de banana

\begin{tabular}{|c|c|c|c|c|c|c|}
\hline \multirow[b]{2}{*}{ Itens } & \multicolumn{4}{|c|}{ Dietas } & \multirow[b]{2}{*}{$\begin{array}{l}\text { CV } \\
(\%)\end{array}$} & \multirow[b]{2}{*}{$\operatorname{Pr}>\mathrm{Fc}$} \\
\hline & $\begin{array}{l}\text { Silagem } \\
\text { de sorgo }\end{array}$ & $\begin{array}{c}\text { Silagem }+ \\
\text { Casca } \\
\text { Banana }\end{array}$ & $\begin{array}{c}\text { Silagem + } \\
\text { Casca Banana } \\
\text { c/ calcário }\end{array}$ & $\begin{array}{l}\text { Silagem + } \\
\text { Casca Banana } \\
\text { c/ óxido de } \\
\text { cálcio }\end{array}$ & & \\
\hline $\begin{array}{l}\text { Tempo alimentação } \\
\text { (h./dia) }\end{array}$ & $6,53^{\mathrm{A}}$ & $6,30^{\mathrm{A}}$ & $5,89^{\mathrm{A}}$ & $5,55^{\mathrm{A}}$ & 12,06 & 0,0624 \\
\hline $\begin{array}{l}\text { Tempo ruminação } \\
\text { (h./dia) }\end{array}$ & $9,07^{\mathrm{B}}$ & $8,83^{\mathrm{AB}}$ & $8,69^{\mathrm{AB}}$ & $8,01^{\mathrm{A}}$ & 7,05 & 0,0137 \\
\hline Tempo ócio (h./dia) & $8,65^{\mathrm{A}}$ & $8,62^{\mathrm{A}}$ & $9,43^{\mathrm{AB}}$ & $10,44^{\mathrm{B}}$ & 8,29 & 0,0002 \\
\hline $\begin{array}{l}\text { Tempo } \\
\text { mastigação/bolo }\end{array}$ & $50,72^{\mathrm{A}}$ & $53,82^{\mathrm{A}}$ & $54,68^{\mathrm{A}}$ & $48,81^{\mathrm{A}}$ & 10,56 & 0,4482 \\
\hline $\begin{array}{l}\text { Número } \\
\text { mastigações/bolo }\end{array}$ & $49,43^{\mathrm{A}}$ & $51,00^{\mathrm{A}}$ & $53,83^{\mathrm{A}}$ & $47,82^{\mathrm{A}}$ & 10,97 & 0,1471 \\
\hline $\begin{array}{l}\text { Número } \\
\text { mastigações/min }\end{array}$ & $61,78^{\mathrm{A}}$ & $63,02^{\mathrm{A}}$ & $62,72^{\mathrm{A}}$ & $60,92^{\mathrm{A}}$ & 5,38 & 0,5895 \\
\hline $\begin{array}{l}\text { Número bolos } \\
\text { ruminados/dia }\end{array}$ & $32.758^{\mathrm{AB}}$ & $34.297^{\mathrm{B}}$ & $32.716^{\mathrm{AB}}$ & $29.456^{\mathrm{A}}$ & 10,01 & 0,0443 \\
\hline $\begin{array}{l}\text { Tempo mastigação } \\
\text { total/h }\end{array}$ & $15,35^{\mathrm{B}}$ & $15,38^{\mathrm{B}}$ & $14,57^{\mathrm{AB}}$ & $13,56^{\mathrm{A}}$ & 5,23 & 0,0002 \\
\hline $\operatorname{EAMS}^{1}\left(\mathrm{~g} \cdot \mathrm{h}^{-1}\right)$ & $2.609,34^{\mathrm{A}}$ & $2.659,37^{\mathrm{A}}$ & $2.921,14^{\mathrm{A}}$ & $2.890,16^{\mathrm{A}}$ & 15,83 & 0,3922 \\
\hline $\operatorname{EAFDN}^{2}\left(\mathrm{~g} \cdot \mathrm{h}^{-1}\right)$ & $1.593,66^{\mathrm{A}}$ & $1.588,90^{\mathrm{A}}$ & $1.749,48^{\mathrm{A}}$ & $1.668,31^{\mathrm{A}}$ & 15,29 & 0,5519 \\
\hline $\operatorname{ERMS}^{3}\left(\mathrm{~g} \cdot \mathrm{h}^{-1}\right)$ & $1.914,64^{\mathrm{A}}$ & $1.831,00^{\mathrm{A}}$ & $1.944,23^{\mathrm{A}}$ & $2.007,10^{\mathrm{A}}$ & 7,30 & 0,1205 \\
\hline $\operatorname{ERFDN}^{4}\left(\mathrm{~g} \cdot \mathrm{h}^{-1}\right)$ & $1.464,95^{\mathrm{A}}$ & $1.090,50^{\mathrm{A}}$ & $1.165,03^{\mathrm{A}}$ & $1.160,87^{\mathrm{A}}$ & 7,59 & 0,2587 \\
\hline
\end{tabular}

${ }^{\mathrm{I}}$ Eficiência de alimentação da matéria seca; ${ }^{2}$ Eficiência de alimentação da FDN; ${ }^{3}$ Eficiência de ruminação da matéria seca; ${ }^{4}$ Eficiência de ruminação da FDN. Médias nas linhas seguidas pela mesma letra não diferem $(\mathrm{P}>0,05)$ entre si pelo teste de Tukey.

Pancoti (2009) estudou o efeito de diferentes tempos de exposição (zero; 24; 48 e 72 horas) do $\mathrm{CaO}$ em $1 \%$ na MN na cana de açúcar, com níveis de $1 \%$ na $\mathrm{MN}$ da mistura de ureia e sulfato de amônio, com relação 9:1, em novilhas Holandês x Zebu, variando de $1 / 4$ a 7/8 de grau de sangue Holandês. Não houve efeito do tempo de exposição à cana de açúcar ao óxido de cálcio sobre os parâmetros de alimentação, ruminação, mastigação, ingestão de água e ócio. Em atividade de alimentação foram gastos $324 \mathrm{~min} /$ dia, em ruminação $548 \mathrm{~min} /$ dia e em ócio $549 \mathrm{~min} /$ dia, valores próximos aos encontrados no presente estudo.

$\mathrm{O}$ aditivo apesar de poder melhorar a qualidade da fibra da casca de banana, não interferiu $(\mathrm{P}>0,05)$ no tempo de mastigação por bolo ruminado, no número de mastigações por bolo $\mathrm{e}$ número de mastigações por minuto (Tabela 5). Entretanto, houve efeito 
Rev. Bras. Saúde Prod. Anim., Salvador, v.17, n.1, p.86-100 jan./mar., 2016 http://www.rbspa.ufba.br ISSN 15199940

significativo $(\mathrm{P}<0,05)$ para o número de bolos ruminados ao dia e tempo de mastigação total. $O$ que pode ser explicado pelo menor tempo de ruminação, especialmente, com a dieta com casca de banana com óxido de cálcio.

$\mathrm{O}$ efeito das dietas sobre as eficiências de alimentação da MS e FDN não foi significativo $(\mathrm{P}>0,05)$, corroborando com os consumos de MS e FDN (Tabela 5). Também não foi verificado efeito significativo das dietas sobre as eficiências de ruminação da MS e da FDN $(\mathrm{P}>0,05)$ (Tabela 5), apesar da redução no tempo de ruminação com a dieta que continha casca de banana com óxido de cálcio. Esse resultado pode ser explicado pelas semelhanças nos consumos de MS e FDN entre as dietas experimentais.

Em concordância com a eficiência de alimentação, a produção total de leite e produção de leite ajustada para $3,5 \%$ de gordura não foram diferentes $(\mathrm{P}>0,05)$ (Tabela 6), podendo-se concluir que a inclusão de $20 \%$ de casca de banana com ou sem aditivo na dieta, em substituição à silagem de sorgo, não prejudicou o aporte de nutrientes para produção média $(16,88 \mathrm{~kg}$ de leite corrigido para $3,5 \%$ de gordura) observada.

Tabela 6. Produção de leite (PL) em kg.dia ${ }^{-1}$, produção de leite corrigido para 3,5\% de gordura em kg.dia ${ }^{-1}$ (PLCG), peso final (PF), variação de peso (VP), escore de condição corporal final (ECCF), mudança de escore de condição corporal (MECC), médias e coeficiente de variação (CV) de vacas em lactação submetidas a dietas com casca de banana

\begin{tabular}{lcccccc}
\hline Itens & \multicolumn{5}{c}{ Tratamentos } & CV \\
\cline { 2 - 5 } & $\begin{array}{c}\text { Silagem de } \\
\text { sorgo }\end{array}$ & $\begin{array}{c}\text { Silagem }+ \\
\text { Casca Banana }\end{array}$ & $\begin{array}{c}\text { Silagem + Casca } \\
\text { Banana c/ calcário }\end{array}$ & $\begin{array}{c}\text { Silagem + Casca } \\
\text { Banana c/ óxido de } \\
\text { cálcio }\end{array}$ & $\begin{array}{c}\text { CV } \\
(\%)\end{array}$ & Pr>Fc \\
\hline PL & $14,28^{\mathrm{A}}$ & $13,80^{\mathrm{A}}$ & $14,60^{\mathrm{A}}$ & $14,23^{\mathrm{A}}$ & 16,29 & 0,9232 \\
PLCG & $17,03^{\mathrm{A}}$ & $16,27^{\mathrm{A}}$ & $17,56^{\mathrm{A}}$ & $16,64^{\mathrm{A}}$ & 14,31 & 0,7411 \\
PF & $483,81^{\mathrm{A}}$ & $473,62^{\mathrm{A}}$ & $471,25^{\mathrm{A}}$ & $474,44^{\mathrm{A}}$ & 6,13 & 0,8343 \\
VP & $11,25^{\mathrm{A}}$ & $5,56^{\mathrm{AB}}$ & $0,94^{\mathrm{AB}}$ & $-6,62^{\mathrm{B}}$ & 36,68 & 0,0145 \\
ECCF & $2,87^{\mathrm{A}}$ & $2,75^{\mathrm{A}}$ & $2,94^{\mathrm{A}}$ & $2,94^{\mathrm{A}}$ & 7,64 & 0,3013 \\
MECC & $0,13^{\mathrm{A}}$ & $0,13^{\mathrm{A}}$ & $0,00^{\mathrm{A}}$ & $0,13^{\mathrm{A}}$ & 27,85 & 0,7141 \\
\hline
\end{tabular}

Médias nas linhas seguidas pela mesma letra não diferem $(\mathrm{P}>0,05)$ entre si pelo teste de Tukey.

Não houve diferença $(\mathrm{P}>0,05)$ no peso final (PF) das vacas, todavia, constatouse diferença na variação de peso $(\mathrm{P}<0,05)$ dos animais, ocorrendo perda de peso apenas com a dieta com casca tratada com óxido de cálcio, que diferiu $(\mathrm{P}<0,05)$ da dieta controle, evidenciando a mobilização de reservas corporais naquele tratamento para manutenção da produção de leite.
O escore de condição corporal final (ECCF) e a mudança no escore de condição corporal (MECC) não foram diferentes em função das dietas $(\mathrm{P}>0,05)$, entretanto, deve-se ponderar para a análise destas variáveis, considerando-se o fato do experimento ser em quadrado latino, com períodos experimentais de 18 dias.

Dormond et al. (1998) trabalhando com vacas em lactação, inicial e 
Rev. Bras. Saúde Prod. Anim., Salvador, v.17, n.1, p.86-100 jan./mar., 2016 http://www.rbspa.ufba.br ISSN 15199940

intermediária, avaliando a produção de leite e seus constituintes, em dois experimentos, utilizando como tratamento $21 \mathrm{~kg}$ e $14 \mathrm{~kg}$ de casca de banana, não observaram efeito significativo dos níveis de casca de banana sobre a produção de leite e nem de seus componentes lácteos. Contudo, independe do nível de inclusão da casca a produção aumentou em $14 \%$, no primeiro experimento e $18 \%$ no segundo experimento, com relação à produção inicial. Os resultados do presente estudo confirmam aos constatados por Dormond et al. (1998), demonstrando o potencial de aproveitamento da casca de banana para produção de leite, o que pode ser estrategicamente importante para redução do custo de produção e do impacto ambiental causado pelo acúmulo de resíduos da agroindústria.

A casca de banana tratada com óxido de cálcio em $20 \%$ da dieta de vacas em lactação reduz o tempo de ruminação, o tempo de mastigação total e o número de bolos ruminados por dia. Entretanto, sem alterar as eficiências de alimentação e ruminação da MS e FDN. A utilização da casca de banana seca ao sol em $20 \%$ da dieta de vacas F1 Holandês / Zebu, não altera produção de leite, com produção média de $16,88 \mathrm{~kg}$ de leite com $3,5 \%$ de gordura.dia ${ }^{-1}$. Entretanto, reduz a digestibilidade da MS e dos nutrientes, podendo limitar o ganho de peso dos animais. A utilização de aditivos na secagem da casca de banana não melhora $\mathrm{o}$ consumo $\mathrm{e}$ produção de leite.

\section{AGRADECIMENTOS}

À FAPEMIG, CNPq e CAPES pelo auxílio com bolsas de estudo.

\section{REFERÊNCIAS}

\author{
ANTUNES, C.R. Qualidade do queijo e \\ do leite de vacas F1 HolandesxZebu \\ alimentadas com casca de banana. \\ 2015. 88f. Dissertação (Mestrado em \\ Zootecnia) - Universidade Estadual de \\ Montes Claros, Janaúba.
}

\section{ASSOCIATION OF ANALITICAL CHEMIST - OAC. Official methods of analysis. 15.ed. Arlington: 1990. 117p.}
BORGES, A.M.; PEREIRA, LUCENA, J.; PEREIRA, E.M. Caracterização da farinha de banana verde. Ciência e Tecnologia de Alimentos, v.29, n.2, p.333-339, 2009.

BÜRGER, P.J.; PEREIRA, J.C.; QUEIROZ, A.C.; SILVA, J.F.C.; VALADARES FILHO, S. C.; CECON, P. R.; CASALI, A.D.P. Comportamento ingestivo em bezerros holandeses alimentados com dietas contendo diferentes níveis de concentrado. Revista Brasileira de Zootecnia, v.29, n.1, p.236-242, 2000.

CARVALHO, G.G.P. de; GARCIA, R.; PIRES, A.J.V.; SILVA, R.R.; RIBEIRO, L.S.O.; CHAGAS, D.M.T.; PINHO, B.D.; DOMICIANO, E.M.B. Consumo, digestibilidade aparente e dias de coleta total na estimativa da digestibilidade em caprinos alimentados com dietas contendo cana-de-açúcar tratada com óxido de cálcio. Revista Brasileira de Zootecnia, v.39, n.12, p.2714-2723, 2010.

CLEMENTINO, R.H.; Utilização de subprodutos agroindústrias em dietas de ovinos de corte, consumo, digestibilidade, desempenho e características de carcaça. 2008. $136 f$. Tese (Doutorado Integrado em Zootecnia) - Universidade Federal do Ceará, Fortaleza. 
Rev. Bras. Saúde Prod. Anim., Salvador, v.17, n.1, p.86-100 jan./mar., 2016 http://www.rbspa.ufba.br ISSN 15199940

DETMANN, E.; SOUZA, M.A.;

VALADARES FILHO, S.C.;

QUEIROZ, A.C.; BERCHIELLI, T.T.; SALIBA, E.O.S.; CABRAL, L.S.; PINA, D.S.; LADEIRA, M.M.; AZEVEDO, J.A.G. Métodos para análise de alimentos. Instituto Nacional de Ciência e Tecnologia de Ciência Animal. 1 ed. Visconde do Rio Branco: Suprema, 2012. 214p.

DETMANN, E.; VALADARES FILHO, S.C. On the estimation of nonfibrous carbohydrates in feeds and diets. Arquivo Brasileiro de Medicina Veterinária e Zootecnia, v.62, p.980984. 2010.

DORMOND, H.; BOSCHINI C.; BOURRIIL, A. R; WATHELET, B.M. Efecto de dos niveles de cascara de banano maduro sobre la produccion lactea en ganado lechero. Agronomía Costarricense, v.22, n.1, p.43-49, 1998.

EMAGA, T.H.; ANDRINAIVO, R.H.; WATHELET, B.; TCHANGO, J.T.; PQUOT, M. Effects of the stage of maturation and varieties on the chemical composition of banana and plantains peels. Food Chemistry, v.103, p.590-600, 2007.

EMAGA, T.H.; BINDELLE, J.; AGNEESENS, R.; BULDGEN, A.; WATHELET, B.M. Ripening influences banana and plantain peels composition and energy content. Tropical Animal Health Production, v.43, n.1, p.171-177, 2011.

FERREIRA, D.F.; Sisvar - Sistema de analise estatistica para dados balanceados. Lavras: DCE- UFLA, 2011.
FERREIRA, M.C.; COSTA, S. M. L.; PASIN, L.A.A. Uso de resíduos da agroindústria de bananas na composição de substratos para produção de mudas de pau pereira. Nativa, v.3, n.2, p.120124, 2015.

GONZALEZ, M.F.; BAS, M.F.; LUQUE, L.V. Effect of the supplementation of hydrogenated fat (GHP) and a calcium salt of fatty acids, derived from fish oil, on in vitro digestibility of cell wall and volatile fatty acids production. Nutrition

Abstract Reviews, v.69, n3, p.797-805, 1998.

JOHNSON, T.R.; COMBS, D.K. Effects of prepartum diet, inert rumen bulk, and dietary polythylene glicol on dry matter intake of lactating dairy cows. Journal of Dairy Science, v.74, n.3, p.933-944, 1991.

LIMA, A.G.B.; NEBRA, S.A.;

QUEIROZ, M.R. Aspectos científico e tecnológico da banana. Revista

Brasileira de Produtos

Agroindustriais, v. 2, n. 1, p. 87-101, 2000 .

MACEDO, T.M. PIRES, A.J.V.; CARVALHO, G.G.P.; BRITO LOPES, W.B.; SOARES, C.O.; CHAGAS, D.M.T. Degradabilidade da matéria seca e da fração fibrosa da cana de açúcar tratada com óxido de cálcio. Revista Brasileira de Saúde Produção Animal [online], v.12, n.2, p.429-440, 2011.

MARTINEZ, T.F.; MOYANO, F.J. Effect of tannic acido on vitro enzymatic hidrolysis of some protein sources. Journal of the Science of Food and Agriculture, v.83, n.5, p.456-464, 2003. 
Rev. Bras. Saúde Prod. Anim., Salvador, v.17, n.1, p.86-100 jan./mar., 2016 http://www.rbspa.ufba.br ISSN 15199940

MONÇÃO, F.P.; REIS, S.T.; RIGUEIRA, J.P.S.; SALES, E.C.J.; GERASEV, L.C.; ALVES, D.D.; ROCHA JUNIOR, V.R.; OLIVEIRA, E.R. Caracterização físico-quimica da casca de banana tratada com óxido de cálcio. Revista de Ciências Agrárias, v.7, n.24, p.339-347, 2014a.

MONÇÃO, F.P.; REIS, S.T.; RIGUEIRA, J.P.S.; SALES, E.C.J.; ANTUNES, A.P.S.; OLIVEIRA, E.R.; CARVALHO, Z.G. Degradabilidade ruminal da matéria seca e da FDN da casca de banana tratada com cal virgem. Revista de Ciências Agrárias, v.37, n.1, p.42-49, 2014b.

MOHAPATRA, D.; MISHRA, S.; SUTAR, N. Banana and its by-product utilisation: an overview. Journal of Scientific e Industrial Research, v.69, p.323-329, 2010.

MURTA, R.M.; CHAVES, M.A.; PIRES, A.J.V.; VELOSO, C.M.; SILVA, F.F. da; ROCHA NETO, A.L.; EUSTÁQUIO FILHO, A.; SANTOS, P.E.F. dos. Desempenho e digestibilidade aparente dos nutrientes em ovinos alimentados com dietas contendo bagaço de cana-de-açúcar tratado com óxido de cálcio. Revista

Brasileira de Zootecnia, v.40, p.13251332, 2011.

NATIONAL RESEARCH COUNCIL NRC. Nutrient requirements of dairy cattle. 7.ed. Washington, D.C: National Academy Press, 2001. 381 p.

OLIVEIRA, L.S.B.; ANDRADE, L.A.; ALVES, A.S.; GONÇALVES, G.S. Substrato e volume de recipiente na produção de mudas de Jatobá (Hymenaea courbaril L.). Nativa, v.2, n.2, p.103-107, 2014.
OLIVEIRA, M.D.S.; BARBOSA, J.C.; MOTA, D.M.; ANDRADE, A.T. Efeito da hidrólise com cal virgem sobre a composição bromatológica da cana-deaçúcar. Veterinária Noticias, v.14, n.1, p.19-27, 2008.

OLIVEIRA, S.G.; BERCHIELLI, T.T. Potencialidades da utilização de taninos na conservação de forragens e nutrição de ruminantes- revisão. Archives of Veterinary Science, v.12, n.1, p.1-9, 2007.

OMER, S. In situdry matter degradation characteristics of banana rejects, leaves, and pseudo stem. Assiut Veterinary Medicine Journal, v.55, n.1, p.120-129, 2009.

PALMQUIST, D.L.; MATTOS, W.R.S. Metabolismo de lipídeos. In:

BERCHIELLI, T.T.; PIRES, A.V.; OLIVEIRA, S.G. (Eds.). Nutrição de ruminantes. Jaboticabal: Funep, 2006. p.287-310.

PANCOTI, C.G. Cana de açúcar tratada com óxido de cálcio, em diferentes tempos de hidrólise, na alimentação de novilhas Holandês $x$ Zebu. 2009. 101f. Dissertação (Mestrado) - Universidade Federal de Minas Gerais, Escola de Veterinária, Belo Horizonte.

PIMENTEL P.R.S. Níveis de inclusão da casca de banana na alimentação de vacas F1 Holândes x Zebu em lactação. 2015.88f. Dissertação (Mestrado em Zootecnia). Universidade Estadual de Montes Claros, Janauba.

RIBEIRO, L.S.O.; PIRES, A.J.; CARVALHO, G.G.P.; CHAGAS, D.M.T. Degradabilidade da matéria seca e da fração fibrosa da cana de açúcar tratada com hidróxido de sódio ou óxido de cálcio. Revista Brasileira de Saúde e Produção Animal [online], v.10, n.3, p.573-585, 2009. 
Rev. Bras. Saúde Prod. Anim., Salvador, v.17, n.1, p.86-100 jan./mar., 2016 http://www.rbspa.ufba.br

SNIFFEN, C.J.; CONNOR, J.D.; VAN SOEST, P.J.; FOX, D.G.; RUSSELL, J.B. A net carbohydrate and protein system for evaluating cattle diets: ii. Carbohydrate and protein availability. Journal of Dairy Science, v.70, n.12, p.3562-3577, 1992.

SKLAN, D.; KAIM, M.; MOALLEN, U.; FOLMAN, Y. Effect of dietary calcium soaps on milk yield, body weight, reproductive hormones, and fertility in first parity and older cows. Journal of Dairy Science, v.77, n.6, p.1652-1660, 1994.

URBANO, S.A.; FERREIRA, M.A.; DUTRA JÚNIOR, W.M.; ANDRADE, R.P.X.; FÉLIX, S.C.R.; CAMPOS, J.T.S.; SIQUEIRA, M.C.B. Substituição do feno de tifton pela casca de mamona na dieta de ovinos: componentes nãocarcaça. Arquivo Brasileiro de Medicina Veterinária e Zootecnia, v.64, p.1649-1655, 2012.

VAN SOEST, P.J. Nutrional ecology of the ruminant. 2.ed. New York: Cornell University Press, 1994. 476p.

VIEIRA, M.M.M.; CÂNDIDO, M.J.D.; BOMFIM, M.A.D.; SEVERINO, L.S.; ZAPATA, J.F.F.; BESERRA, L.T.; MENESES, A.J.G.; FERNANDES, J.P.B. Características da carcaça e dos componentes não-carcaça em ovinos alimentados com rações à base de farelo de mamona. Revista Brasileira de Saúde e Produção Animal [online], v.11, n.1, p.140-149, 2010.
WILDMAN, E.E.; JONES, G.M.; WGNER, P.E.; BOMAN, R.L.; TROUTT, H.F.; LESCH, T.N. A dairy condition scoring system and its relationship to selected production characteristics. Journal of Dairy Science, v.65, n.3, p.495-498, 1982.

Data de recebimento: $14 / 12 / 2015$ Data de aprovação: 08/02/2016 